\title{
Effects of an Interaction Between Inoculum Density and Temperature on Germination of Puccinia allii Urediniospores and Leek Rust Progress
}

\author{
Tijs Gilles and Roy Kennedy
}

Horticulture Research International, Wellesbourne, Warwickshire CV35 9EF, UK.

Accepted for publication 9 October 2002.

\section{ABSTRACT}

Gilles, T., and Kennedy, R. 2003. Effects of an interaction between inoculum density and temperature on germination of Puccinia allii urediniospores and leek rust progress. Phytopathology 93:413-420.

Controlled environment experiments were conducted to study the effects of inoculum density, temperature, and their interaction on germination of Puccinia allii urediniospores and infection of leek leaves. Percent germination of $P$. allii urediniospores and percent branching of germ tubes increased with density of urediniospores and approached a plateau for densities above $\approx 20$ spores $\mathrm{cm}^{-2}$ of leaf area. Percent germination was highest at 12 to $21^{\circ} \mathrm{C}$, a wide-range temperature optimum. Branching occurred at temperatures ranging from 5 to $25^{\circ} \mathrm{C}$, but there were few germ tubes branching at $25^{\circ} \mathrm{C}$. P. allii successfully infected leek leaves at temperatures ranging from 7 to $22^{\circ} \mathrm{C}$. The number of pustules produced increased with urediniospore density on leek leaves. At low spore densities, pustule production was little affected by tempera-

Leek rust, caused by the pathogen Puccinia allii, is an important disease affecting leek crops (Allium porrum), and occurs in the United Kingdom (24,25), Germany (16), the Netherlands (8), China (12), and Taiwan (13). The presence of rust pustules on leek plants reduces the quality of the product and thus the crop's market value. Severe epidemics can even result in complete crop loss.

Such epidemics develop only when (i) a sufficient amount of inoculum of $P$. allii enters a crop and (ii) the conditions are suitable for disease development. The amount of primary inoculum of $P$. allii that enters a leek crop was found to be related to the rate of disease progress and severity of rust within the crop (7). Thus, density of urediniospores of $P$. allii on leaf surfaces is likely to be an important variable affecting disease progress. Furthermore, temperature is thought to affect disease progress, because observations of rust in leek crops suggested that the rate of disease progress was reduced at times when temperatures were lower.

Progress and severity of leek rust are the results of several underlying fungal developmental processes such as urediniospore germination, infection, latent period, and pustule production. Temperature and density of urediniospores of $P$. allii could affect these developmental processes and thereby affect the resulting progress and severity of leek rust epidemics. Several examples for this can be found for related rust pathogens on other crops. For example, germination of urediniospores was affected by (i) temperature for $P$. menthae on peppermint (9), P. substriata var. indica on pearl millet (26), and $P$. triticina and $P$. graminis f. sp. tritici on wheat (15); and (ii) by spore density on leaf surfaces for $P$. polysora on corn (17). Temperature was found to affect latent periods of $P$.

Corresponding author: T. Gilles; E-mail address: tijs.gilles@hri.ac.uk

Publication no. P-2003-0122-02R

(C) 2003 The American Phytopathological Society ture; at higher spore densities, pustule production was greatest between 9 to $11^{\circ} \mathrm{C}$, and numbers of pustules decreased greatly with temperature increasing above this optimum. Latent period was affected by temperature, with latent period being shortest between 19 and $22^{\circ} \mathrm{C}$, and latent period increasing when temperature decreased. Latent periods became $\approx 1.8$ days shorter for every 10 -fold increase in spore density. The rate of pustule production increased with increasing spore density on leaves and was greatest between 11 to $14^{\circ} \mathrm{C}$. Computer simulation of leek rust progress based on the found relationships suggested that at optimal temperatures the development of leek rust epidemics may be little affected by initial spore density and density caused by each pustule, but that at sub- and supra-optimal temperatures the development is greatly affected by these variables.

Additional keywords: Allium porrum, disease progress, infection rate, modeling.

lagenophorae on groundsel (14) and P. graminis on perennial ryegrass and tall fescue (22). Experimental evidence suggests that latent periods can decrease with increasing spore density. This was found for $P$. hordei on barley $(5,27)$ and for other species of fungal leaf pathogens: Colletotrichum truncatum on lentils (6), Rhynchosporium secalis on winter barley (28), and Peronospora parasitica on radish (1). Temperature and spore density also affected lesion development of these pathogens. Experimental evidence is needed for the effects of an interaction between temperature and inoculum density on leek rust development.

This paper presents results of a controlled environment study on the effects of temperature and urediniospore density on spore germination and infection of leek by $P$. allii. Relationships between temperature and spore density and leek rust infection are modeled and used in a simulation study of disease progress under different initial spore densities at different temperatures. The simulation study may predict under which temperature and density conditions epidemics are likely to occur in leek crops.

\section{MATERIALS AND METHODS}

Plant material and $\boldsymbol{P}$. allii isolate. Leek 'Wintra' seedlings were transplanted into square 9 -cm-diameter pots 1 month after sowing and were raised in a glasshouse. The plants were inoculated when they had reached 7- to 8-leaf stage, which was after 3 months, when grown in summer, and after up to 6 months, when grown in winter. An isolate of $P$. allii, obtained from a leek crop at Wellesbourne in the UK in 1999, was used to inoculate all experiments. The isolate was maintained on leek 'Wintra' in a glasshouse. Spores were collected by a suction pump into a vial and suspended in distilled water. A hemacytometer was used to adjust the concentration of urediniospores in suspension.

Measuring urediniospore density. A method was developed to measure the density of urediniospores of $P$. allii on surfaces of 
leek leaves to study the effects of spore density on infection. Leek plants were inoculated with suspensions of urediniospores $(5 \times$ $10^{2}, 1 \times 10^{3}, 5 \times 10^{3}, 1 \times 10^{4}$, and $1 \times 10^{5}$ urediniospores per $\mathrm{ml}$ ) to obtain different spore densities on the leaf surfaces. Each spore suspension was sprayed for $15 \mathrm{~s}$ over two 9-cm-diameter square pots, each containing four plants, by an airbrush spray gun (Student ISB 500; Revell, Bünde, Germany) attached to an air pump (Capex 2D-C; Charles Austen Pumps Ltd., Weybridge, UK; pump rate 8.5 liters of air $\min ^{-1}$ at 1.5 bar pressure). Two glass microscope slides were placed between the plants prior to each inoculation. Inoculation ensured that spores were deposited both on leaves and on glass slides. The amount of inoculum that was sprayed over the plants did not cause droplets to run off, which would have caused a difference in deposition between the horizontal glass slides and the nearly vertical leek leaves. Following inoculation, spores were counted per area of leaf by observation through a dissecting microscope at $\times 50$ magnification and per area of slide through a compound microscope at $\times 100$ magnification. For each inoculation, the density of spores was counted on two glass slides (area of each glass slide: $76 \times 26 \mathrm{~mm}^{2}$ ) and five sections $(5 \mathrm{~cm}$ long) of leaves. The experiment was conducted twice. The data for numbers of spores per area of slide and numbers of spores per area of leaf were $\log _{10}$-transformed and average values and standard errors were calculated. The method of Patefield (20) was used to fit a linear functional relationship between the transformed values for spore density per area of glass slide and transformed values for spore density per area of leaf with the statistical software Genstat 5 release 4.2 (VSN International Ltd., Oxford, UK). This method fits a linear relationship by taking account of the bidirectional standard errors for each data point.

Effects of temperature and urediniospore density on spore germination. Plants were inoculated by an airbrush spray gun (Student ISB 500) with spore suspensions of different concentrations $\left(10^{5}, 5 \times 10^{4}, 10^{4}, 5 \times 10^{3}, 10^{3}\right.$, and $5 \times 10^{2}$ spores $\left.\mathrm{ml}^{-1}\right)$ and placed in controlled environment cabinets (Sanyo 970; Sanyo Gallenkamp PLC, Loughborough, UK; 12-h light/12-h dark cycle with $150 \mu \mathrm{mol} \mathrm{m} \mathrm{m}^{-2} \mathrm{~s}^{-1}$ light intensity) at $5,8,12,16,21$, and $25^{\circ} \mathrm{C}$ and leaf wetting for $12 \mathrm{~s}$ every $10 \mathrm{~min}$. The temperatures were randomly allocated to each cabinet. The plants were taken out of the cabinets $48 \mathrm{~h}$ after inoculation, and the leaf surfaces were dried with a fan for 10 to $15 \mathrm{~min}$. A $20 \%$ solution of collodion (Fisher Chemicals, Loughborough, UK) in ethanol was spread onto leaf surfaces with a brush and left to dry. The collodion formed a plastic film preserving all structures on the epidermic surface including fungal spores. The collodion films were removed from the leaves and placed on droplets of water on microscope glass slides, which enabled the films to spread out. The collodion films were left to air dry on to the glass slides, and a few droplets of a $0.1 \%$ solution of trypan blue (Sigma, Poole, UK) in lactophenol were added before mounting. The slides were examined at $\times 100$ magnification. The numbers of germinated and nongerminated spores and the numbers of branched and nonbranched germ tubes were counted. The total area of observed collodion film was measured by an eyepiece with a grid. The actual density of spores on the observed collodion films was calculated as numbers of spores per area of collodion film. Each combination of temperature and spore density treatments was applied to two pots containing four leek plants. The experiment was conducted twice. Branching of germ tubes was counted in only one experiment.

An exponential model was fitted by the software Genstat to combined data of both experiments to describe percent germination of $P$. allii spores $(g)$ as a function of density of spores on the leaf surface $(d)$ for each temperature separately:

$$
g=a_{g}-f_{g}\left(v_{g}\right)^{d} \quad 0<v_{g}<1
$$

Parameter $a_{g}$ is the maximum percent germination of spores and is approached by the curve with increasing spore density. Percent

TABLE 1. Combinations of temperature and Puccinia allii urediniospore density treatments that were applied to study progress of leek rust in two controlled environment experiments

\begin{tabular}{|c|c|c|c|c|c|c|c|}
\hline Experiment & Temp. $\left({ }^{\circ} \mathrm{C}\right)$ & $\begin{array}{l}\text { Conc. spore suspension } \\
\text { (no. spores } / \mathrm{ml})\end{array}$ & $\begin{array}{c}\text { Spore density } \\
\left(\text { no. spores } / \mathrm{cm}^{2} \text { leaf }\right)^{\mathrm{a}}\end{array}$ & Experiment & Temp. $\left({ }^{\circ} \mathrm{C}\right)$ & $\begin{array}{l}\text { Conc. spore suspension } \\
\text { (no. spores/ml) }\end{array}$ & $\begin{array}{c}\text { Spore density } \\
\text { (no. spores } / \mathrm{cm}^{2} \text { leaf) }\end{array}$ \\
\hline 1 & 7.7 & $\begin{array}{l}5 \times 10^{2} \\
1 \times 10^{3} \\
5 \times 10^{3} \\
1 \times 10^{4} \\
1 \times 10^{5}\end{array}$ & $\begin{array}{c}0.1 \\
1.1 \\
2.8 \\
22 \\
40\end{array}$ & 2 & 12.2 & $\begin{array}{l}5 \times 10^{2} \\
1 \times 10^{3} \\
5 \times 10^{3} \\
1 \times 10^{4} \\
1 \times 10^{5}\end{array}$ & $\begin{array}{c}1.4 \\
2.1 \\
6.7 \\
14 \\
140\end{array}$ \\
\hline 1 & 16.3 & $\begin{array}{l}5 \times 10^{2} \\
1 \times 10^{3} \\
5 \times 10^{3} \\
1 \times 10^{4} \\
1 \times 10^{5}\end{array}$ & $\begin{array}{r}0.2 \\
0.4 \\
1.5 \\
11.1 \\
99\end{array}$ & 2 & 16.0 & $\begin{array}{l}5 \times 10^{2} \\
1 \times 10^{3} \\
5 \times 10^{3} \\
1 \times 10^{4} \\
1 \times 10^{5}\end{array}$ & $\begin{array}{r}0.8 \\
1.6 \\
6.6 \\
12 \\
202\end{array}$ \\
\hline 2 & 9.1 & $\begin{array}{l}5 \times 10^{2} \\
1 \times 10^{3} \\
5 \times 10^{3} \\
1 \times 10^{4} \\
1 \times 10^{5}\end{array}$ & $\begin{array}{r}0.6 \\
0.6 \\
6.4 \\
7.5 \\
171\end{array}$ & 2 & 22.1 & $\begin{array}{l}5 \times 10^{2} \\
1 \times 10^{3} \\
5 \times 10^{3} \\
1 \times 10^{4} \\
1 \times 10^{5}\end{array}$ & $\begin{array}{r}0.7 \\
1.4 \\
4.5 \\
8.9 \\
157\end{array}$ \\
\hline
\end{tabular}

${ }^{a}$ Spore density per area of leaf surface was calculated from measurements of spore density per area of glass slide with the regression equation shown in Figure 1. 
germination approaches the value $a_{g}-f_{g}$ when spore density approaches 0 . Parameter $v_{g}$ determines how quickly the maximum percent germination of urediniospores is reached with increasing spore density. A similar model, $b=a_{b}-f_{b}\left(v_{b}\right)^{d}$, was fitted to data for percent branching of germ tubes $(b)$ with urediniospore density. The estimates of parameters $a_{g}, b_{g}$, and $v_{g}$ or $a_{b}, b_{b}$, and $v_{b}$ were tested for significant differences among temperatures.

Disease progress. Disease progress was studied on leek plants that were inoculated with different spore densities and placed in controlled environment cabinets at different temperatures in two experiments. Approximately $12 \mathrm{ml}$ of a spore suspension $\left(5 \times 10^{2}\right.$, $1 \times 10^{3}, 5 \times 10^{3}, 1 \times 10^{4}$, and $1 \times 10^{5}$ urediniospores $\mathrm{ml}^{-1}$ ) was sprayed with an airbrush spray gun (Student ISB 500) over three pots with four leek plants per pot for each temperature $\times$ spore density treatment. Directly after inoculation, plants were placed in controlled environment cabinets (Sanyo 970; 12-h light/12-h dark cycle with $150 \mu \mathrm{mol} \mathrm{m} \mathrm{m}^{-2} \mathrm{~s}^{-1}$ light intensity) running at constant temperatures of $6.9,7.7,16.3$, and $20.3^{\circ} \mathrm{C}$ in experiment 1 and $9.1,10.1,12.2,16.0,19.8$, and $22.1^{\circ} \mathrm{C}$ in experiment 2 . Inoculated plants were kept wet within the cabinets by automatic spraying of fine water droplets for $12 \mathrm{~s}$ every $10 \mathrm{~min}$ for $48 \mathrm{~h}$. Glass slides had been placed between the plants prior to inoculation and the density of spores was determined on one slide for each temperature $\times$ spore density treatment combination. Estimates of the density of spores on the inoculated leek leaves were calculated using the linear relationship between the density of spores on slides and spores on leaves (derived as described previously). The combinations of temperature and spore density treatments are summarized in Table 1. Every 1 to 4 days for approximately 55 days, the numbers of leaves and rust pustules were counted and the number of pustules per leaf was calculated from these observations. Pustules were only counted when their color had become bright orange to red, which coincided with pustules becoming infectious.

Modeling the effects of temperature and urediniospore density. Gompertz functions, of the form $p=c \exp \{-\exp [-b(t-m)]\}$, were fitted with the standard curves directive within Genstat to the data for numbers of pustules per leaf $(p)$ with time $(t$; in days) for each combination of temperature and urediniospore density in each experiment; estimates of $c, b$, and $m$ were obtained. The parameters $b$ and $m$ of this function were reparameterized to $b=$ $2.72 \mathrm{r} / \mathrm{c}$ (the value 2.72 is the base value of the natural logarithm) and $m=l$ to describe disease progress as a function of the param-

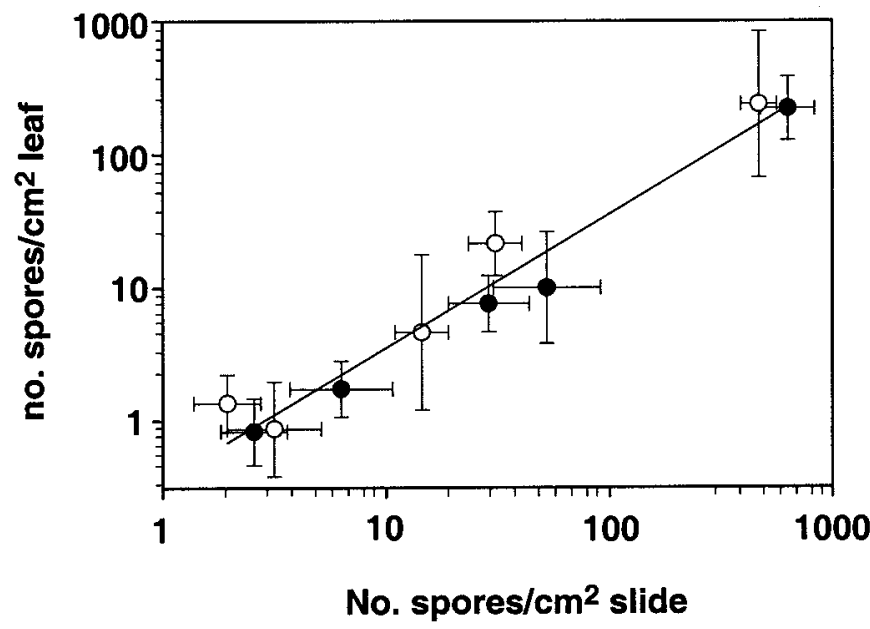

Fig. 1. Regression of density of Puccinia allii urediniospores on a leek leaf $\left(s_{l} ; \log _{10}\right.$-transformed) onto density of urediniospores on microscope glass slides $\left(s_{s} ; \log _{10}\right.$-transformed); $\log _{10} s_{l}=-0.45+1.00 \log _{10} s_{s}, R^{2}=0.95$. The data was obtained in two experiments $(\bullet$ and $\circ)$. The error bars show the standard errors. eters total number of pustules produced $(c)$, latent period of $P$. allii $(l$; in days), and rate of increase in number of pustules per day $(r)$ :

$$
p=c \exp \left\{-\exp \left[-\left(\frac{2.72 r}{c}\right)(t-l)\right]\right\}
$$

The reparameterization was done in order to include the epidemiologically important parameters latent period and rate of disease increase in the function. This function estimates latent period as the time from inoculation until the rate of pustule production is greatest and occurs when $37 \%$ of the total number of pustules have been produced. The value $37 \%$ is determined by the Gompertz function $(=1 / 2.72)$. The parameters have been described in previous work by Gilles et al. (11).

Estimates of $c$ ( $\log _{10}$-transformed), $l$, and $r$ ( $\log _{10}$-transformed) were regressed to temperature $(T)$ and urediniospore density $(S)$ $\left(\log _{10}\right.$-transformed):

$$
\begin{gathered}
\log _{10}(c+1)=k_{1}+k_{2} \log _{10}(S+1)+k_{3} T+k_{4} T^{2}+k_{5} \log _{10}(S+1) T^{2} \\
l=m_{1}+m_{2} T+m_{3} T^{2}+m_{4} \log _{10}(S+1) \\
\log _{10}(r)=n_{1}+n_{2} \log _{10}(S+1)+n_{3} T+n_{4} T^{2}
\end{gathered}
$$

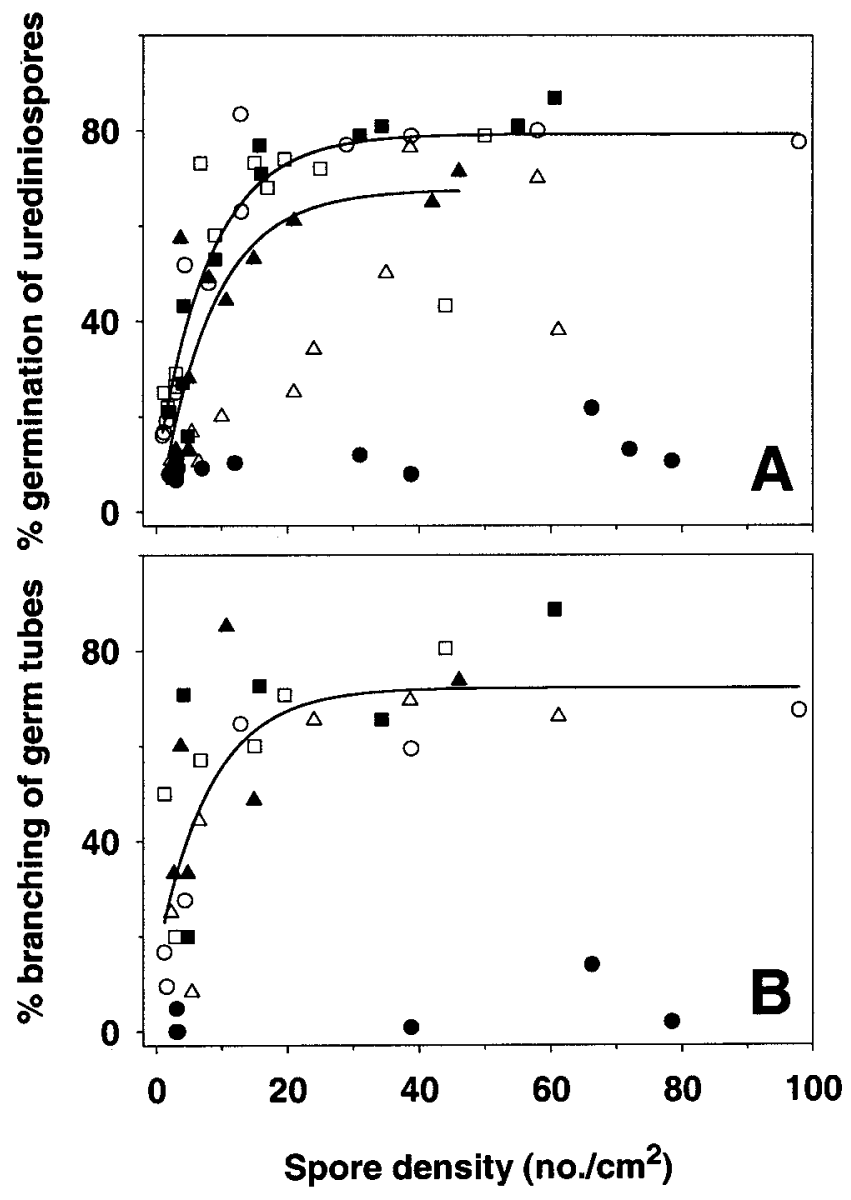

Fig. 2. A, Percent germination of Puccinia allii urediniospores and $\mathbf{B}$, percent branching of germination hyphen in relation to density of urediniospores on leek leaf surfaces at $5(\Delta), 8(\mathbf{\Delta}), 12(\square), 16(\square), 21(\circ)$, and $25^{\circ} \mathrm{C}(\bullet)$. Equation 1 was fitted to describe percent germination $(g)$ in relation to density $(d)$ at $8^{\circ} \mathrm{C}\left(g=68-70(0.89)^{d}\right)$ and at 12 to $21^{\circ} \mathrm{C}\left(g=79-71(0.89)^{d}\right)$ $\left(P<0.001 ; R^{2}=0.84\right)$, and to describe percent branching of germination hyphen $(b)$ in relation to density at 5 to $21^{\circ} \mathrm{C}\left(b=72-57(0.88)^{d}\right)(P<$ $\left.0.001 ; R^{2}=0.73\right)$. 


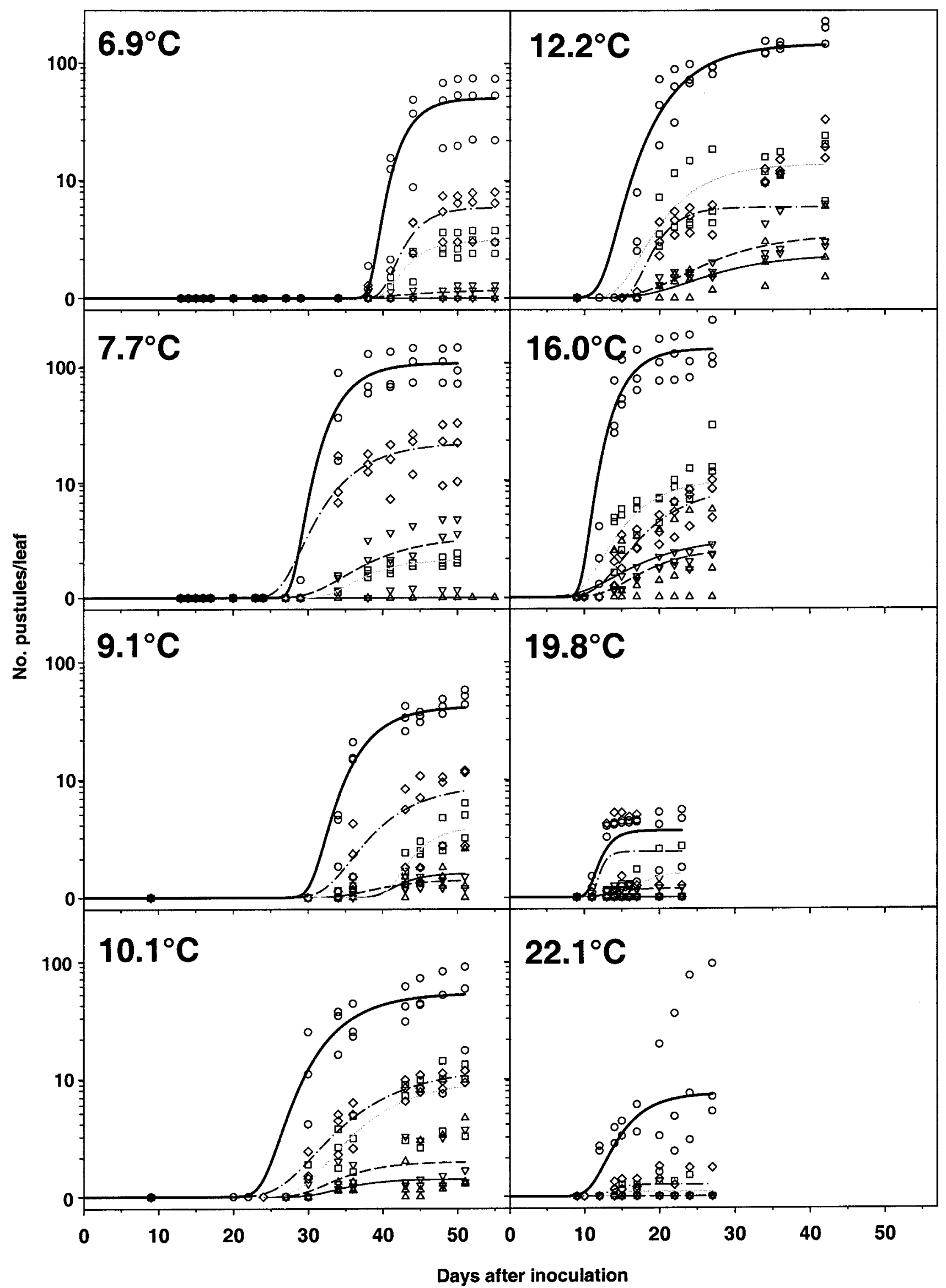

Fig. 3. Numbers of pustules per leaf $\left(\log _{10}(\right.$ value +1$)$-transformed scale) with time after inoculation of leek plants with $5 \times 10^{2}(\Delta), 1 \times 10^{3}(\nabla), 5 \times 10^{3}(\square), 1 \times$ $10^{4}(\diamond)$, and $1 \times 10^{5}(\circ)$ Puccinia allii urediniospores per $\mathrm{ml}$ at 6.9 and $7.7^{\circ} \mathrm{C}$ in experiment 1 or at $9.1,10.1,12.2,16.0,19.8$, and $22.1^{\circ} \mathrm{C}$ in experiment 2 . Lines indicate fitted Gompertz functions. 
A Student's $t$ test was done to test for the significance of the estimated parameters. The fitted models were used to produce response-surface curves to graphically present parameters $c, l$, and $r$ in relation to temperature and spore density.

Simulation of disease progress. A study was done to simulate by computer calculation the progress of leek rust epidemics initiated with 0.2 spores per $\mathrm{cm}^{2}$ of leaf compared with epidemics initiated with 2 spores per $\mathrm{cm}^{2}$ of leaf at 8,14 , and $20^{\circ} \mathrm{C}$. Various assumptions were made. It was assumed that spores were dispersed after the latent period of $P$. allii had elapsed. Pustules were assumed to remain infectious for 20 days and to produce the same amount of spores every day during this 20 -day period. The infectious period of $P$. allii is unknown. The 20-day infectious period corresponds with observations on spore production by $P$. triticina (23). Care should be taken in assessing the results of this simulation because spore production is likely not to be constant with time, and the duration of the infectious period and the amount of spores produced can be affected by temperature and spore density $(14,23)$. It was further assumed that conditions were always suitable for infection. The leek crop in this simulation was seen as a homogenous surface without loss or gain of leaves. There was no information available about the density of spores a single pustule of $P$. allii on a leaf could cause. This depends on the dispersal of spores with distance from a single pustule. In this simulation study two scenarios were investigated. One in which each pustule causes a density of 0.1 spore per $\mathrm{cm}^{2}$ of leaf, and the other, where each pustule causes a density of 1 spore per $\mathrm{cm}^{2}$ of leaf. The higher spore density on a leaf relates to a location in close proximity of the spore-producing uredosori. The number of pustules with time was calculated with the Gompertz model (model 2) by inputting values for parameters $c, l$, and $r$, which were calculated with models 3,4 , and 5 , respectively.

\section{RESULTS}

Measuring urediniospore density. A good linear relationship was found between transformed values for density of $P$. allii urediniospores on glass slides, which were located between plants during inoculation, and transformed values for density of urediniospores on leaves (Fig. 1). The relationship accounted for $95.2 \%$ of the variation in the data, and the standard error of observations was estimated to be 0.20 .

Effects of temperature and urediniospore density on spore germination. The germination of urediniospores of $P$. allii increased greatly with spore density increasing to $\approx 20$ spores $\mathrm{cm}^{-2}$ of leaf and reached a plateau for further increases in spore density (Fig. 2A). Temperature also affected germination, which was highest at 12 to $21^{\circ} \mathrm{C}$. Germination decreased with temperature increasing from 21 to $25^{\circ} \mathrm{C}$ or with temperature decreasing from 12 to $5^{\circ} \mathrm{C}$. Equation 1 describes the data for germination well at 8 , 12,16 , and $21^{\circ} \mathrm{C}$, but did not fit to data for germination at 25 and $5^{\circ} \mathrm{C}$. One curve was fitted to data for 12,16 , and $21^{\circ} \mathrm{C}$, because estimates of $a_{g}, f_{g}$, and $v_{g}$ did not differ between these temperatures $(P=0.78,0.10$, and 0.19 , respectively). A separate curve was fitted to data for $8^{\circ} \mathrm{C}$, because estimates of $a_{g}$ and $f_{g}$ differed from those obtained for 12 to $21^{\circ} \mathrm{C}(P<0.001$ and 0.001 , respectively).

Germ tube morphology was affected by $P$. allii urediniospore density and temperature (Fig. 2B). The percent branching of germ tubes increased with urediniospore density increasing to $\approx 20$ spores $\mathrm{cm}^{-2}$ of leaf, and reached a plateau for further increases in spore density. A model based on equation 1 was fitted to data for 12 to $21^{\circ} \mathrm{C}$, but not to data for $25^{\circ} \mathrm{C}$, because the data approached a linear curve.

Disease progress. Successful infection of leek leaves by $P$. allii urediniospores was observed at all temperatures tested (Fig. 3), ranging from 6.9 to $22.1^{\circ} \mathrm{C}$. However, the numbers of pustules produced at the higher temperatures, 20.3 and $22.1^{\circ} \mathrm{C}$, were greatly reduced. Pustules were produced with as little as 0.2 to 1.4 spores $\mathrm{cm}^{-2}$ of leaf at temperatures ranging from 6.9 to $20.3^{\circ} \mathrm{C}$. At $22.1^{\circ} \mathrm{C}$, greater densities of spores were required to successfully infect leek leaves. For example, at $22.1^{\circ} \mathrm{C}$, pustules were not observed at spore densities of 0.7 and 1.4 spores $\mathrm{cm}^{-2}$ of leaf and only 2 pustules were observed on 22 leaves when 4.5 spores $\mathrm{cm}^{-2}$ of leaf were applied. The number of pustules produced after infection generally increased with increasing spore density on leaves. The fitted Gompertz curves generally described the data well, except at $22.1^{\circ} \mathrm{C}$ and a spore density of 157 spores $\mathrm{cm}^{-2}$ of leaf, where the pustule data was highly variable. Furthermore, the Gompertz function did not fit well to the pustule data observed at $22.1^{\circ} \mathrm{C}$ and 4.5 spores $\mathrm{cm}^{-2}$ of leaf because only 2 pustules were observed for this treatment.

Latent periods of $P$. allii were 12 to 17 days at 20.3 to $22.1^{\circ} \mathrm{C}$. However, latent period increased with decreasing temperature. At $6.9^{\circ} \mathrm{C}$, the longest latent period of $P$. allii of 43 days was observed. At all temperatures, latent periods of $P$. allii were shorter for the highest spore density on leaves compared with the lowest spore density. The rate of pustule production per day generally increased with increasing spore density on leaves at the time of infection, and was low at the higher temperatures, 20.3 and $22.1^{\circ} \mathrm{C}$.

The estimates of $c, l$, and $r$ were well described as functions of temperature and spore density by equations 3,4 , and 5 , respectively. The parameters included in these equations were significant (Table 2) and unbiased. Response-surface curves illustrating parameters $c, l$, and $r$ in relation to temperature and spore density on

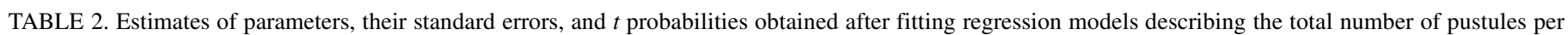

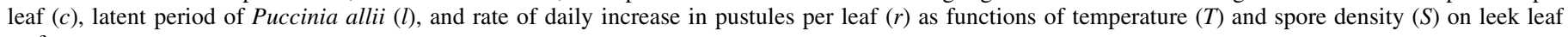
surfaces

\begin{tabular}{|c|c|c|c|c|}
\hline Equations & Parameter & Estimate & SE & $t$ probability \\
\hline \multicolumn{5}{|l|}{ Total number of pustules per leaf } \\
\hline \multirow[t]{5}{*}{$\log _{10}(c+1)=k_{1}+k_{2} \log _{10}(S+1)+k_{3} T+k_{4} T^{2}+k_{5} \log _{10}(S+1) T^{2}$} & $k_{1}$ & -0.90 & 0.382 & 0.022 \\
\hline & $k_{2}$ & 0.99 & 0.103 & $<0.001$ \\
\hline & $k_{3}$ & 0.15 & 0.059 & 0.012 \\
\hline & $k_{4}$ & -0.0055 & 0.00206 & 0.011 \\
\hline & $k_{5}$ & -0.0011 & 0.00037 & 0.005 \\
\hline \multicolumn{5}{|l|}{ Latent period of $P$. allii } \\
\hline \multirow[t]{4}{*}{$l=m_{1}+m_{2} T+m_{3} T^{2}+m_{4} \log _{10}(S+1)$} & $m_{1}$ & 84.9 & 4.42 & $<0.001$ \\
\hline & $m_{2}$ & -6.80 & 0.691 & $<0.001$ \\
\hline & $m_{3}$ & 0.17 & 0.024 & $<0.001$ \\
\hline & $m_{4}$ & -1.79 & 0.625 & 0.007 \\
\hline \multicolumn{5}{|l|}{ Rate of daily increase in pustules per leaf } \\
\hline \multirow[t]{4}{*}{$\log _{10}(r)=n_{1}+n_{2} \log _{10}(S+1)+n_{3} T+n_{4} T^{2}$} & $n_{1}$ & -2.30 & 0.553 & $<0.001$ \\
\hline & $n_{2}$ & 1.02 & 0.080 & $<0.001$ \\
\hline & $n_{3}$ & 0.17 & 0.084 & 0.049 \\
\hline & $n_{4}$ & -0.0069 & 0.00293 & 0.023 \\
\hline
\end{tabular}


leaves, in which transformed parameters were back-transformed, show the effects of temperature and spore density on leaves more clearly (Fig. 4). The number of pustules produced following a single infection event increased with spore density on leaves; the increase in pustules produced per leaf with increasing spore density was greatest at 9 to $11^{\circ} \mathrm{C}$. Under conditions of low density of spores on leaves, which often occur under natural conditions in the field, small numbers of pustules were produced over a wide range of temperatures. For example, model 3 suggests that when 0.5 to 3 spores are applied per square centimeter of leaf $\approx 1$ pustule is produced at temperatures ranging from 7 to $20^{\circ} \mathrm{C}$. Under conditions of high density of spores on leaves, the number of pustules produced decreases more rapidly with increasing temperature. For example, at a density of 80 spores $\mathrm{cm}^{-2}$ of leaf, model 3 suggests that 40 pustules are produced at $14.5^{\circ} \mathrm{C}$. An increase in temperature to $17.5,19.8$, or $21.5^{\circ} \mathrm{C}$ decreases pustule production to 20 ,

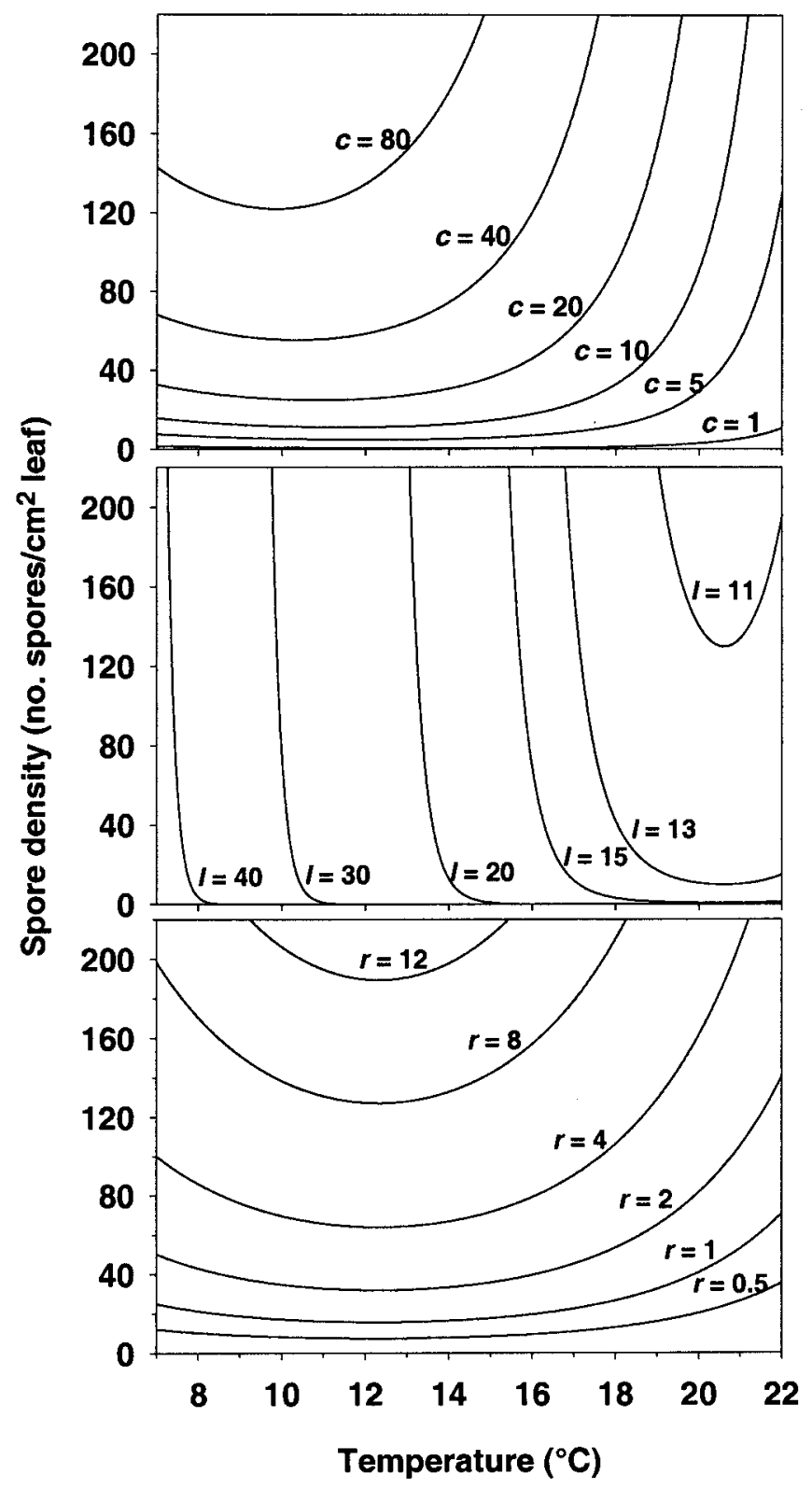

Fig. 4. Response-surface curves of leek rust infection parameters $c$ (= total number of pustules produced per leaf), $l$ (= latent period of Puccinia allii defined as the time from inoculation until the rate of pustule production is greatest), and $r$ (= maximum rate of increase in number of pustules per day in a monocyclic infection) against temperature $\left({ }^{\circ} \mathrm{C}\right)$ and urediniospore density (number of spores per centimeter of leaf).
10 , or 5 pustules per leaf. This is the effect of the fitted negative $\log _{10}($ spore density +1$) \times(\text { temperature })^{2}$ interaction term (Table 2 ). Latent period is mainly affected by temperature, with latent period being shortest between 19 and $22^{\circ} \mathrm{C}$, and latent period increasing with decreasing temperatures. Spore density has a considerable effect on latent period. Latent periods are $\approx 1.8$ days shorter for every 10-fold increase in spore density (Table 2). The rate of pustule production increases with increasing spore density on leaves and is affected little by temperature at low densities of spores on leaves. At greater spore densities on leaves, $r$ is greatest at 11 to $14^{\circ} \mathrm{C}$.

Simulation of disease progress. At $14^{\circ} \mathrm{C}$, all epidemics progressed when initiated with either 0.2 or 2 spores $\mathrm{cm}^{-2}$ of leaf. It was found that at 8 and $20^{\circ} \mathrm{C}$ and low initial spore densities (0.2 spore $\mathrm{cm}^{-2}$ of leaf), the number of newly produced pustules was insufficient to cause the same number of new pustules in following infection cycles and epidemic progress eventually halted (Fig. 5). For example, when it was assumed that each pustule causes a spore density of 0.1 spore $\mathrm{cm}^{-2}$ of leaf, it was found that epidemics initiated with 0.2 spore $\mathrm{cm}^{-2}$ of leaf at 8 or $20^{\circ} \mathrm{C}$ or 2 spores $\mathrm{cm}^{-2}$ of leaf at $20^{\circ} \mathrm{C}$ produced increasingly less pustules in each following infection cycle, causing epidemic progress to halt. When it was assumed that each pustule causes a spore density of 1 spore $\mathrm{cm}^{-2}$ of leaf, epidemics initiated with 0.2 spore $\mathrm{cm}^{-2}$ of leaf at $8^{\circ} \mathrm{C}$ and 2 spores $\mathrm{cm}^{-2}$ of leaf at $20^{\circ} \mathrm{C}$ did progress, but the epidemic initiated with 0.2 spore $\mathrm{cm}^{-2}$ of leaf at $20^{\circ} \mathrm{C}$ still did not progress. Changes in initial spore density had little effect on disease progress at $14^{\circ} \mathrm{C}$, which is near the optimum for $P$. allii. However, changes in initial spore density had a great effect on disease progress at 8 and $20^{\circ} \mathrm{C}$, which are sub- and supra-optimal temperatures, respectively, when each pustule was assumed to cause a density of 1 spore $\mathrm{cm}^{-2}$ of leaf.

\section{DISCUSSION}

The results of these controlled environment experiments demonstrate that temperature and urediniospore density of $P$. allii on leaves affect urediniospore germination, latent period, and pustule production by $P$. allii on leek plants; these factors, therefore, affect the progress of leek rust epidemics in leek crops. Our results confirm previous observations of a reduction in the progress of leek rust epidemics in the field at low densities of inoculum (7). The results from controlled environment experiments on the effects of temperature on latent period of $P$. allii also confirm observations from the same previous field experiments of a slower progress of leek rust during times when temperature was reduced.

The optimum temperature for germination of $P$. allii urediniospores ranged from 12 to $20^{\circ} \mathrm{C}$. This suggests that the pathogen is well adapted to a wide range of temperatures which occur frequently in the United Kingdom. Similarly, wide-range temperature optima for urediniospore germination were found for other related rust pathogens. For example, the optima for $P$. graminis f. sp. tritici and $P$. triticina ranged from 6 to $28^{\circ} \mathrm{C}$ for both species (15), the optimum for $P$. striiformis (yellow rust on barley) ranged from 5 to $15^{\circ} \mathrm{C}(19)$, and the optimum for $P$. substriata var. indica ranged from 16 to $25^{\circ} \mathrm{C}$ (26). The results also showed that germination of urediniospores decreased rapidly with an increase in temperature from 21 to $25^{\circ} \mathrm{C}$. Similarly, germination of $P$. striiformis and $P$. menthae urediniospores were greatly reduced for increases in temperature above the optimum $(9,19)$.

The results demonstrate an effect of spore density on urediniospore germination of $P$. allii. There was an increase in percent urediniospore germination with spore density increasing to 20 spores $\mathrm{cm}^{-2}$ of leaf area. This suggests that urediniospores of $P$. allii are stimulated to germinate when they occur at high densities on a leek leaf surface. In studies on the germination of urediniospores of $P$. graminis f. sp. tritici, a water-soluble compound was found within urediniospores, which inhibited spore germination 
when it occurred in high concentrations. Dilution of the compound stimulated germination, but at a high dilution the compound did not affect germination $(2,3,10)$. A similar compound may also be present within $P$. allii urediniospores and may affect their germination when urediniospores are present at different densities on leaves. Frequently, urediniospores are dispersed in clusters of several spores. Clustering of spores could enhance germination, because percent germination of clusters of urediniospores of $P$. triticina and Uromyces appendiculatus is greater than single urediniospores of these species (4). The observations of germinated urediniospores of $P$. allii in this study further suggest that the morphology of germ tubes, in terms of branching of germ tubes, is also affected by temperature and spore density on leaves. A higher percent branching of germ tubes is related to a higher success rate of germ tubes finding stomata and causing infections. The branching of $P$. graminis f. sp. tritici germ tubes was also affected by temperature (15).

The results of these controlled environment studies suggest that infection is affected by a complex interaction between temperature and spore density on leaves. The observed increase in pustule production with increasing density of $P$. allii urediniospores was also observed for $P$. graminis f. sp. tritici $(18,21)$. Furthermore, it was found with the latter fungus that the total number of pustules produced reached a plateau when spore density increased above $4 \times 10^{4}$ spores per leaf (18), which suggests saturation of the capacity of a leaf to produce pustules. A plateau in pustule production may also occur for $P$. allii, but this was not observed in this study, because infection was not studied at such high inocu- lum densities. An interesting finding in the current study was that at high spore densities, the number of pustules produced after infection decreased greatly with temperature increasing above the optimum, and this was reflected by a decrease in percent germination of urediniospores. Similarly, a great decrease in pustule production for an increase in temperature above the optimum was also found for $P$. menthae, and this was associated with a decrease in germination of urediniospores (9).

Latent period was mainly affected by temperature. However, the observed decrease in latent period of $\approx 1.8$ days per 10 -fold increase in spore density for spore densities ranging between 0.1 and 200 spores $\mathrm{cm}^{-2}$ of leaf was significant and confirms that spore density can affect latent period as previous research results suggest $(1,5,6,27,28)$. It is possible that a more rapid depletion of nutrient and assimilate resources at higher densities of fungal colonies within leaves enhances earlier reproduction of the pathogen before such resources have been depleted.

The simulation study suggests that at optimal temperatures leek rust epidemics will progress for a wide range of initial spore densities, whereas at sub- and supra-optimal temperatures, a greater initial spore density is required for epidemics to progress. Such interaction between temperature and spore density in relation to epidemic development is a novel aspect in the study of disease epidemics and may occur for several airborne pathogens. Little information is available about such interaction between environment, spore density, and disease progress. However, experiments under field conditions are required to provide more evidence for this.

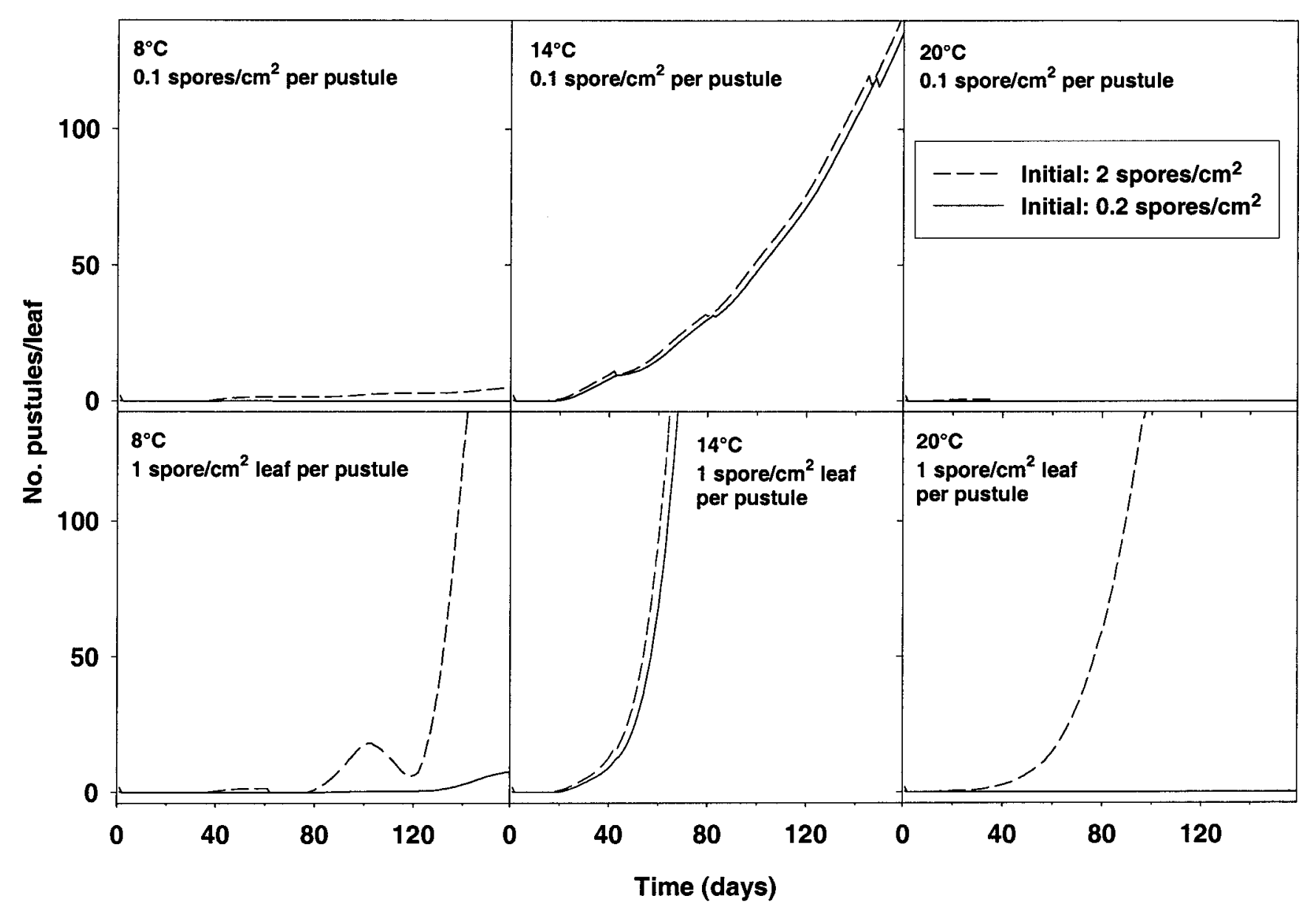

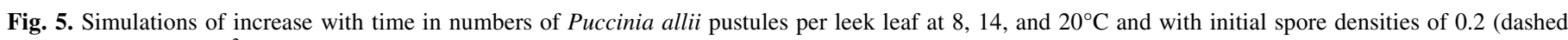

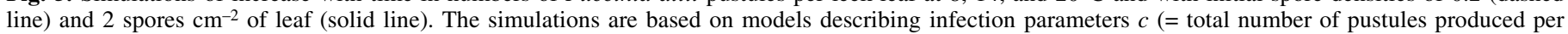

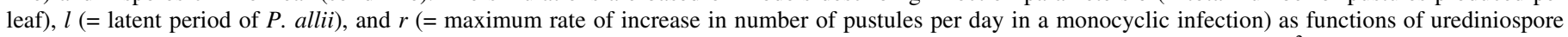

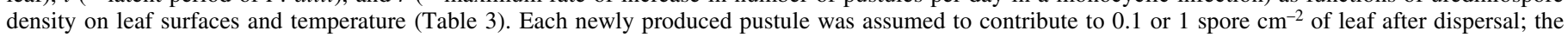
latter corresponding to a location in the crop in closer proximity to a highly infectious source. 


\section{ACKNOWLEDGMENTS}

We thank the UK Department for Environment, Food and Rural Affairs (DEFRA) for their financial support of this work, and K. Phelps at HRI for helpful comments on the statistics.

\section{LITERATURE CITED}

1. Achar, P. N. 1992. Dose-response relationship of Peronospora parasitica in Raphanus sativus. Phyton-Int. J. Exp. Bot. 53:83-87.

2. Allen, P. J. 1957. Properties of a volatile fraction from uredospores of Puccinia graminis var. tritici affecting their germination and development. I. Biological activity. Plant Physiol. 32:385-389.

3. Allen, P. J. 1955. The role of a self-inhibitor in the germination of rust uredospores. Phytopathology 45:259-266.

4. Aylor, D. E., and Ferrandino, F. J. 1986. Germination of urediniospore clusters of Uromyces appendiculatus and Puccinia recondita. Trans. Br. Mycol. Soc. 86:591-595.

5. Baart, P. G. J., Parlevliet, J. E., and Limburg, H. 1991. Effects of infection density on the size of barley and wheat leaf rust colonies before and on the size of uredia after the start of sporulation. J. Phytopathol. 131:59-64.

6. Chongo, G., and Bernier, C. C. 2000. Effects of host, inoculum concentration, wetness duration, growth stage, and temperature on anthracnose of lentil. Plant Dis. 84:544-548.

7. Clarkson, J. P., Kennedy, R., Phelps, K., Davies, J., and Bowtell, J. 1997. Quantifying the effects of reduced doses of propiconazole (Tilt) and initial disease incidence on leek rust development. Plant Pathol. 46:952963.

8. de Jong, P. D., Daamen, R. A., and Rabbinge, R. 1995. The reduction of chemical control of leek rust, a simulation study. Eur. J. Plant Pathol. 101:687-693.

9. Edwards, J., Parbery, D. G., Halloran, G. M., and Taylor, P. A. 1998. Assessment of infection and sporulation processes of Puccinia menthae on peppermint in controlled conditions. Aust. J. Agric. Res. 49:11251132

10. French, R. C., Massey, L. M., and Weintraub, R. L. 1957. Properties of a volatile fraction from uredospores of Puccinia graminis var. tritici affecting their germination and development. II. Some physical and chemical properties. Plant Physiol. 32:389-393.

11. Gilles, T., Fitt, B. D. L., Welham, S. J., Evans, N., Steed, J. M., and Jeger, M. J. 2001. Modelling the effects of temperature and wetness duration on development of light leaf spot on oilseed rape leaves inoculated with Pyrenopeziza brassicae conidia. Plant Pathol. 50:42-52.

12. Huang, J. W. 1994. Control of Chinese leek rust with a plant nutrient formulation. Plant Pathol. Bull. 3:9-17.

13. Ko, Y., and Sun, S. K. 1993. Ecological studies on the Chinese leek rust in Taiwan. Chih Wu Pao Hu Hsueh Hui Hui K'An 35:1-13.

14. Kolnaar, R. W., and van den Bosch, F. 2001. Effect of temperature on epidemiological parameters of Puccinia lagenophorae. Plant Pathol. 50:363-370.

15. Kramer, C. L., and Eversmeyer, M. G. 1992. Effect of temperature on germination and germ-tube development of Puccinia recondita and $P$. graminis urediniospores. Mycol. Res. 96:689-693.

16. Krauthausen, H. J., Richter, E., and Hommes, M. 1999. Integrated pest management in horticultural crops-control thresholds in leeks and onions. Schriftenr. Bundesminist. Ernaehr. Landwirtsch. Forsten R. A. Angew. Wiss. 485.

17. Melching, J. S. 1981. The effect of inoculum density on uredospore germination and infection of corn by Puccinia polysora, the cause of southern corn rust. Phytopathology 71:769.

18. Newton, M. R., Kinkel, L. L., and Leonard, K. J. 1997. Competition and density-dependent fitness in a plant parasitic fungus. Ecology 78:17741784.

19. Osman-Ghani, N., and Manners, J. G. 1983. Effect of temperature on germination and viability of urediniospores of four races of Puccinia striiformis from barley. Trans. Br. Mycol. Soc. 81:241-245.

20. Patefield, W. M. 1977. On the information matrix in the linear functional relationship problem. Appl. Stat. 26:69-70.

21. Petersen, L. J. 1959. Relations between inoculum density and infection of wheat by uredospores of Puccinia graminis var. tritici. Phytopathology 49:607-614.

22. Pfender, W. F. 2001. A temperature-based model for latent-period duration in stem rust of perennial ryegrass and tall fescue. Phytopathology 91:111-116.

23. Sache, I. 1997. Effect of density and age of lesions on sporulation capacity and infection efficiency in wheat leaf rust (Puccinia recondita $\mathrm{f}$. sp. tritici). Plant Pathol. 46:581-589.

24. Smith, B. M., and Crowther, T. C. 1992. Field assessment of the reaction of leek cultivars to leek rust. In: Tests of Agrochemicals and Cultivars, Issue 13. Ann. Appl. Biol. 120(suppl.):104-105.

25. Smith, B. M., Crowther, T. C., Clarkson, J. P., and Trueman, L. 2000. Partial resistance to rust (Puccinia allii) in cultivated leek (Allium ampeloprasum ssp. porrum): Estimation and improvement. Ann. Appl. Biol. 137:43-51.

26. Tapsoba, H., and Wilson, J. P. 1997. Effects of temperature and light on germination of urediniospores of the pearl millet rust pathogen, Puccinia substriata var. indica. Plant Dis. 81:1049-1052.

27. Teng, P. S., and Close, R. C. 1978. Effect of temperature and uredinium density on urediniospore production, latent period, and infectious period of Puccinia hordei Otth. New Zeal. J. Agric. Res. 21:287-296.

28. Xue, G. X., and Hall, R. 1992. Effects of surface wetness duration, temperature, and inoculum concentration on infection of winter barley by Rhynchosporium secalis. Phytoprotection 73:61-68. 